Published as: J.P. van der Sluijs and W. Turkenburg, Climate Change and the Precautionary Principle. In: Elizabeth Fisher, Judith Jones and René von Schomberg, Implementing The Precautionary Principle, Perspectives and Prospects, ELGAR, 2006 chapter 12, page 245-269

\title{
Climate change and the Precautionary Principle
}

Jeroen P. van der Sluijs and Wim C. Turkenburg

Copernicus Institute for Sustainable Development and Innovation, Utrecht University,

Heidelberglaan 2,3584CS Utrecht,The Netherlands, j.p.vandersluijs@chem.uu.nl

\section{Introduction}

Scientific assessment of the risks of anthropogenic climate change has shown that there is a reasonable concern for the possibility of irreversible large-scale adverse effects on the long term. Examples of such effects are a severe reduction or shut down of the Gulf Stream and the North Atlantic current, accelerated species extinction and extreme sea level rise. But, deep scientific uncertainty on causality, timing, probability and magnitude of such adverse effects persists. This meets all the criteria of the definition of the Precautionary Principle (PP) adopted in this book:

"Where, following an assessment of available scientific information, there is reasonable concern for the possibility of adverse effects but scientific uncertainty persists, provisional risk management measures based on a broad cost/benefit analysis whereby priority will be given to human health and the environment, necessary to ensure the chosen high level of protection in the Community and proportionate to this level of protection, may be adopted, pending further scientific information for a more comprehensive risk assessment, without having to wait until the reality and seriousness of those adverse effects become fully apparent." (Von Schomberg, 2004)

In theory, the international community has acknowledged that the PP needs to be invoked here. In Art. 3.3 of the United Nations Framework Convention on Climate Change (UN-FCCC, 1992) it is stated that: "The Parties should take precautionary measures to anticipate, prevent or minimize the causes of climate change and mitigate its adverse effects. Where there are threats of serious or irreversible damage, lack of full scientific certainty should not be used as a reason for postponing such measures, taking into account that policies and measures to deal with climate change should be cost-effective so as to ensure global benefits at the lowest possible cost." In practice however, actions have been delayed and postponed. The Kyoto protocol has watered down in the successive negotiations on the details of its mechanisms. Also, the level of protection for the climate case chosen by for instance the EU is increasingly challenged.

In this chapter we will review the management of climate risks from the viewpoint of the PP. Following the ingredients of the definition of the PP, we first explore the grounds for concern with a focus on potential irreversible large-scale adverse effects and associated uncertainties. Next we explore the issue of the chosen level of protection for climate change. Finally we discuss the implications of the PP for climate risk management and the science policy interface.

\section{The risks of anthropogenic climate change}

In the geological past, major global climate changes have occurred. These changes had natural causes, such as variation in the distance between the sun and the Earth, changes in solar luminosity, meteor impact, volcanic activity and continental drift.

Over the past 8000 years, climate on Earth has been relatively stable, which has been a key factor in the development of humanity. This development however brought far- 
reaching changes in land use and vegetation patterns (disappearance of old growth forests, emergence of agriculture and cattle breeding etc.) along with exponential growth in the use of commodities to fulfill the energy and material demand of the fast growing world population. As a consequence, the emission of greenhouse gasses (such as $\mathrm{CO}_{2}, \mathrm{CH}_{4}, \mathrm{~N}_{2} \mathrm{O}, \mathrm{SF}_{6}, \mathrm{CFCs}$ and HFCs) has increased to a point where it has changed the composition of the atmosphere significantly.

Analysis of the composition of air-bubbles trapped in ice in the Vostoc ice core suggests that in the past 420,000 years the $\mathrm{CO}_{2}$ concentration has varied between $180 \mathrm{ppmv}$ (parts per million by volume) during ice ages and $280 \mathrm{ppmv}$ in the inter-glacial periods (Petit et al., 1999). Since the first industrial revolution, the atmospheric $\mathrm{CO}_{2}$ concentration has increased from the equilibrium concentration of $280 \mathrm{ppmv}$ in 1750 to nearly $380 \mathrm{ppmv}$ in 2005 . For all greenhouse gases together, the $\mathrm{CO}_{2}$-equivalent concentration is now more than 450 ppmv. Present-day atmospheric greenhouse gas concentrations thus exceed the natural variability of the past half million years.

After 10 years of Earth system research, the International Geosphere Biosphere Programme concluded that the human enterprise drives multiple, interacting effects that cascade through the Earth System in complex ways. The Earth's dynamics are characterized by critical thresholds and abrupt changes. Human activities could inadvertently trigger changes with catastrophic consequences for the Earth System. The Earth System has moved well outside the range of natural variability exhibited over the last half million years at least. The nature of changes now occurring simultaneously in the global environment, their magnitudes and rates, are evaluated as unprecedented in human history. According to Steffen and Tyson (2001), the Earth is now operating in a no-analogue state.

Assessment of the risks of climate change is based on a number of insights: understanding of the physical laws that govern the climate, historic trends, scenario analysis and model calculations. The increase in atmospheric greenhouse gas concentrations adds to the well known natural greenhouse effect of the atmosphere by absorbing and re-emitting infrared radiation emitted by the Earth surface, thereby increasing the net downward flux of infrared radiation emitted by atmosphere. The extra downward flux of infrared radiation to the Earth surface through this mechanism compared to the pre-industrial equilibrium energy balance of the earth is called the "radiative forcing" of the climate. The extend to which this radiative forcing leads to changes in climate (temperature, evaporation and precipitation, circulation patterns etc) depends on the complex interactions of a large number of poorly understood feedback loops in the Earth system.

State of the art climate research as reviewed by the Intergovernmental Panel on Climate Change (IPCC; Houghton et al., 2001) shows that globally, the average Earth surface temperature has increased by $0.7 \pm 0.2^{\circ} \mathrm{C}$ since the late 19th century. The largest increase has occurred over the past 20 to 30 years. At the North pole the observed temperature change is twice as big. In Europe, the observed warming is $0.95^{\circ} \mathrm{C}$ (European Environment Agency, 2004). Temperatures in winter have increased more than in summer. The observed rate of global warming is now $0.17 \pm 0.05^{\circ} \mathrm{C}$ per decade. The seawater temperature has also increased. Differences in temperature increase between sea and land lead to changes in circulation patterns. Increased evaporation of 
water has led to a $2 \%$ increase of precipitation over land. More important than the average rainfall is that at many places on Earth big changes in precipitation patterns have been observed, both positive and negative.

The IPCC concluded in their second (Houghton et al., 1996) and third (Houghton et al., 2001) scientific assessment report that the observed climate change is for a substantial part attributable to human activities.

Scenario studies by the IPCC (Nakicenovic and Swart, 2000; Houghton et al., 2001) have shown that human activity is likely to lead to further climate change with possibly severe impacts. It should be noted that even if atmospheric composition were fixed today, temperature would continue to rise because thermal inertia of the oceans causes the realized warming to lag several decades behind changes in radiative forcing. Moreover, temporary aerosol cooling masks part of the greenhouse warming. A recent study by Wigley (2005) showed that committed warming for present day atmospheric greenhouse gas concentrations could exceed an additional $1{ }^{\circ} \mathrm{C}$ on top of the $0.7^{\circ} \mathrm{C}$ that has already been realized.

However, without additional policies, greenhouse gas concentrations are projected to rise to 650 - $1215 \mathrm{ppmv}$, which could lead to a global mean temperature increase in 2100 of 1.5 to $6^{\circ} \mathrm{C}$ compared to 1990 . These projection have been made using seven different climate models assuming a climate sensitivity - the equilibrium change in global mean temperature resulting from a doubling of atmospheric carbon dioxide concentrations - in the range 1.7 to $4.2^{\circ} \mathrm{C}$. Recent uncertainty analysis of the sensitivity of the climate to changes in greenhouse forcing suggest that uncertainty in climate sensitivity spans up a wider range. Using the technique of ensemble modeling to explore the propagation of model parameter uncertainty in the Hadley Centre Global Climate Model, Murphy et al., (2004) found a 5-95\% probability range for climate sensitivity of $2.4-5.4^{\circ} \mathrm{C}$. Stainforth et al. (2005) found climate sensitivities on the high end of the range up to $11.5^{\circ} \mathrm{C}$. Based on probability density functions representing uncertainty in climate sensitivity taken from eight different studies, Dessai and Hulme (2004) show that, while there appears to be confidence in the lower bound of climate sensitivity, the central value (50th percentile of the distribution) ranges from 2 to $6^{\circ} \mathrm{C}$. The range for the upper bound (for instance the 95th percentile) is even wider: it ranges roughly from 5 to $9^{\circ} \mathrm{C}$ across the eight attempts to quantify the uncertainty. Projected ranges published by IPCC in 1996 and 2001 do not reflect these uncertainties. Further, IPCC projects and reports the transient temperature change for the year 2100, whereas committed climate change in that year is higher. Finally, one has to bear in mind that regional climate change can be significantly smaller (e.g. near the equator) or larger (especially near the poles).

The impacts of projected climate change are expected to be manifold. Because of limited understanding of a large number of feedback loops in the complex Earth system and inherent limitations to the predictability of climate on the local and regional spatial scales, uncertainty in climate projections are huge and partly irreducible. Effects can become manifest gradually and linear, but also non-linear as a singular event. Gradual changes include the increase of temperature, sea level rise, melting of glaciers, increase in length of the growth season, increase in precipitation and increase of extreme weather events such as heat waves and super storms. Examples of non-linear effects are the possible strong reduction or even shut down of the so called thermohaline circulation in 
the oceans (which could lead to a cooling of North and North-West Europe), disintegration of gas hydrates in melting permafrost and in the oceans (which leads to massive emissions of the greenhouse gas methane), disintegration of the West Antarctic Ice Sheet or strongly increased melting of the Greenland Ice Sheet (which may lead to several meters of sea level rise on the long term).

\section{Poorly known probability, high impact events}

A number of possible irreversible large-scale non-linear impacts of climate change has been identified, ranging from a regime shift in the thermohaline ocean circulation and sea level rise of several meters to extinction of species and loss of unique ecosystems, migration of human populations (environmental refugees), changes in frequency and intensity of extreme weather events, reduction of food security and changes in the geographical distribution of diseases. Although our state of knowledge suggests that on the long term such impacts are plausible, it is not possible to quantify the magnitude and probability of each of these potential effects especially at regional and local level. At the same time, the observed climate change in the past decades has led to several unanticipated impacts. An example of such a surprise is a recent collapse of a dike in the Netherlands (August, 2003) in a period of extreme drought, leading to the flooding of a village. The dike was made of local soil and it turned out that peat in the dike had dried out by which it had lost so much weight that the dike could no longer withstand the pressure of the water. It was then realized that the Netherlands has thousands of kilometers of dike made of local soil that contains peat. A large scale monitoring system has now been set up to assure early detection of peat drying in dikes. Never in history had this type of dike been exposed to such extreme drought and nobody had thought of this scenario. Because models anticipate climate change well beyond the natural variability of the climate in the past millennia, the climate may move outside of the part of the so called "parameter hyper space" on which our knowledge of the dynamics of the present climate system is based. This implies that more unanticipated impacts and surprises are likely to occur.

In the following we review in more detail grounds for concern of three poorly-knownprobability, high-impact events that may occur in a warming world: a shut down of the thermohaline circulation in the oceans, extreme sea level rise through disintegration of ice masses and accelerated (massive) species extinction.

\section{Thermohaline circulation}

The Gulf Stream and the North Atlantic current are part of a larger ocean circulation system known as the thermohaline circulation (THC). The THC is driven by gradients in temperature and salinity and it transports large amounts of heat to the North Atlantic regions. It strongly determines present day climates in Western and Northern Europe. The main "pump" that drives the THC is the North Atlantic deep water formation: the combined effects of evaporation during the Northward transport and cooling and formation of sea ice in the North Atlantic increase the salinity and density of the water to a point where it sinks. Theoretical and paleoclimatic evidence point to the possibility of rapid changes in the THC. Global warming is likely to lead to an extra influx of fresh water in the North Atlantic through increased rainfall and increased amounts of melting water, while with higher temperatures less sea ice is formed an thus less fresh water extracted from the sea water. This could decrease salinity and density of the surface sea 
water to a threshold point where it stops sinking which would imply a shut down of the THC. Model studies show that such a shut down once it occurs is quasi permanent due to a so called 'hysteresis' in the systems response to changes in fresh water input: the fresh water input has to go back to a point far below the shut-down threshold point before the THC is switched on again, which may take several centuries.

Paleologic evidence shows that such regime shifts in the THC have occurred several times in the geological past. This evidence also indicates potentially large regional climate impacts (Alley, 2003). Model studies suggest that a shut down of the THC could lead to a local cooling of several degrees in the North Atlantic region within a few decades (Rahmstorf, 1995; Stocker et al., 2001). A study with the UK Hadley Centre climate model showed that in the first decade after the extreme case of a total shutdown of the THC, the annual mean cooling in the UK might be $3-5^{\circ} \mathrm{C}$ and $2-3^{\circ} \mathrm{C}$ in the third decade. To put these numbers in context: typical decadal mean cooling during the Little Ice Age period was for the UK in the order of magnitude of $0.5^{\circ} \mathrm{C}$ and the coldest individual year in the UK during the Little Ice Age was 1740 with an anomaly in annual mean temperature of $-2.5^{\circ} \mathrm{C}$ (Wood et al., 2003). Such a cooling of the Nothern hemisphere would reduce local evaporation, precipitation and wind regimes and global circulation patterns, which in combination with the regional cooling may lead to wide range of severe impacts on ecosystems, agriculture, economies etc..

It is unknown what the threshold point is to trigger a shut down of the THC and where the present THC is on the hysteresis curve that describes North Atlantic deep water formation as a function of fresh water input. Hence it is also not yet possible to assess whether this threshold point can be reached for any of the projected climate change scenarios presently considered. Some experts believe that there is a $50 \%$ chance that a shut down occurs for a global warming of $4-5^{\circ} \mathrm{C}$. The present day Global Climate Models fed with IPCC's emission scenarios show a gradual weakening, but not a shut down of the THC. Simplified Earth System models however have shown the possibility of a shut down under plausible greenhouse gas forcings. (Wood et al, 2003) Deutch et al. (2002) argue that the present ocean observation system is so incomplete and infrequent that it would detect a change in THC intensity only after the point at which climate policy would be able to respond with effective mitigation.

\section{Extreme sea level rise}

In the assessments of the risk of sea level rise trough anthropogenic climate change, four factors play a role: thermal expansion of sea water, ice-sheet dynamics, natural trends and other man-made causes of sea level rise (mainly ground water extraction). The ice sheet dynamics constitutes the most problematic factor in the assessments of future sea level as it harbors the largest uncertainties and can be non-linear. In table 1 the present ice volumes and sea-level equivalents of the Earth are given. If all ice on Earth would melt, the worldwide average sea level would rise about 80 meters. 


\begin{tabular}{lcc}
\hline & Ice volume $\left(10^{6} \mathrm{~km}^{3}\right)$ & Sea level rise equivalent $(\mathrm{m})$ \\
\hline East Antarctica & 25.92 & 64.8 \\
West Antarctica & 3.40 & 8.5 \\
Greenland & 3.0 & 7.6 \\
Small ice caps and & 0.12 & 0.3 \\
mountain glaciers & & \\
Permafrost & $0.03-0.7$ & $0.08-0.17$ \\
\hline
\end{tabular}

Table 1 Ice components of land ice and their sea level rise equivalents (Titus, 1986).

The mass balance of ice sheets is quite complicated. Increase of temperature at the poles leads to increased evaporation of seawater and increased snowfall, positively contributing to the mass balance. At the same time the melting rate increases, which is a negative contribution. Morphological aspects (profiles of the bottom, shape and thickness of the ice shelves etc.) are a third factor, as they influence calving and streaming of the ice.

The research into the behavior of ice sheets was originally part of a scientific discussion on the causes of sea level changes in the recent geological past. The debate on the stability of the West Antarctic Ice Sheet (WAIS) was initiated by John H. Mercer, a glaciologist. He was interested in the dramatic sea level changes during the last glaciation. He developed a hypothesis that sought to explain interglacial high sea levels by the deglaciation of West Antarctica. This hypothesis pointed out that fringing ice shelves, which are essential for the continued existence of an ice sheet grounded far below sea level, must consist of 'cold' ice below the pressure melting point, and will rapidly disintegrate by calving, if the average temperature of the warmest month rises above freezing point at sea level. (Mercer, 1970)

This theory opposed the accepted theory of Emiliani, which suggested that the high interglacial sea levels were the result of significant melting of the Greenland Ice Sheet. In 1978, Mercer linked up for the first time the stability of the WAIS with anthropogenic climate change. He suggested in an article in "Nature" that: "If the global consumption of fossil fuels continues to grow at its present rate, atmospheric $\mathrm{CO}_{2}$ content will double in about 50 years. Climate models suggest that the resultant greenhouse warming effect will be greatly magnified in high latitudes. The computed temperature rise at latitude 80 degrees South could start rapid deglaciation of West Antarctica, leading to a 5 meter rise in sea level." and:

"... deglaciation of West Antarctica would probably be the first disastrous result of continued fossil fuel consumption. ... If so, major dislocations in coastal cities, and submergence of low lying areas such as much of Florida and the Netherlands, lies ahead."

Mercer's theory gave rise to public concern and to a scientific debate on the stability of the WAIS. Further research in the 1980s pointed in the direction that the WAIS might be more stable than hitherto assumed and anticipated warming in the coming century would not be large enough to initiate the complete melting of the West Antarctic ice shelves. (Van der Veen and Oerlemans, 1987). It should be noted that this assessment was biased by the time horizon chosen of one century, which is short in comparison to 
the typical time scales of ice sheet dynamics and does not account for committed warming. Later assessments exhibit the same bias. The first IPCC report concludes in 1990: "Within the next century, it is not likely that there will be a major outflow of ice from West Antarctica due directly to global warming." (Houghton et al.,1990). In the third assessment report (Houghton et al., 2001) IPCC concludes that, ice-dynamic instability of the WAIS and accelerated sea level rise are very unlikely during the $21 \mathrm{st}$ century for the range of projected warming. However, for warming of more than $10^{\circ} \mathrm{C}$, simple runoff models predict that a zone of net mass loss would develop on the ice sheet surface. Irreversible disintegration of the WAIS would result because the WAIS cannot retreat to higher ground once its margins are subjected to surface melting and begin to recede. According to IPCC, once started, such disintegration would take at least a few millennia.

The thresholds for total disintegration of the East Antarctic Ice Sheet by surface melting is estimated to be about $20^{\circ} \mathrm{C}$ warming (Houghton et al., 2001).

The Greenland ice sheet is the most vulnerable to climate warming but is not as potentially instable as the WAIS, meaning that the melting would be a more gradual process. Models project that a local annual-average warming of larger than $3^{\circ} \mathrm{C}$ sustained for millennia would lead to virtually a complete melting of the Greenland ice sheet. For a local warming over Greenland of $5.5^{\circ} \mathrm{C}$ the Greenland ice sheet contributes about $3 \mathrm{~m}$ in 1,000 years. For a warming of $8^{\circ} \mathrm{C}$, the contribution is about $6 \mathrm{~m}$, the ice sheet being largely eliminated. (Houghton et al., 2001)

\section{Species extinction}

Shifting climate zones may lead to habitat loss and thereby to species extinction. Using projections of species' distributions for future climate scenarios, Thomas et al. (2004) assessed extinction risks for sample regions that cover some $20 \%$ of the Earth's terrestrial surface. On the basis of mid-range climate-warming scenarios for 2050, they found that $18-35 \%$ of species will be 'committed to extinction'. Note that committed to future extinction as a consequence of climate change over the next 50 years is not the same as the number of species that will become extinct during this period. Information is not currently available on time lags between climate change and species-level extinctions, but decades might elapse between area reduction (from habitat loss) and extinction. Land use should also be incorporated into analyses: extinction risks might be higher than projected by Thomas et al. if future locations of suitable climate do not coincide with other essential resources (such as soil type or food resources). According to the UN Millennium Ecosystem Assessment (2005) observed changes in climate, especially warmer regional temperatures, have already had significant impacts on biodiversity and ecosystems in many parts of the world. There have been changes in species distributions, population sizes and the timing of reproduction or migration events, as well as an increase in the frequency of pest and disease outbreaks, especially in forested systems.

Although it is not possible to determine whether the extreme temperatures were a result of human-induced climate change, many coral reefs have undergone major, although often partially reversible, bleaching episodes when sea surface temperatures have increased during one month by $0.5-1{ }^{\circ} \mathrm{C}$ above the average of the hottest months. Extensive coral mortality has occurred with observed local increases in temperature of $3^{\circ} \mathrm{C}$. 
The Millennium Ecosystem Assessment further concludes that by the end of the century, climate change and its impacts may be the dominant direct driver of biodiversity loss and changes in ecosystem services globally. It will increase the risk of extinction for many species, especially those already at risk due to factors such as low population numbers, restricted or patchy habitats and limited climatic ranges.

\section{The chosen level of protection}

In risk management a widely used approach is agreeing on a normative choice for an acceptable risk level for the risky activity and putting enough measures in place to keep the risk below that level. This is problematic for three reasons. First, the degree to which people consider a risk acceptable or not depends not only on the magnitude of the damage and the probability that damage will occur, but on other risk dimensions as well. A given risk tends to be seen as less acceptable if the (perceived) controllability of consequences is lower; if the nature of the consequences is unfamiliar and dreadful; if one is exposed to the risk involuntarily; if the benefits of the activity are less clear and smaller; if the effects are more acute and more nearby in space and time; if risk and benefits are unfairly distributed; and if the likely harm is intentional (Vlek, 2004). Second, attitudes towards risks vary from person to person and across cultures. Some people have a risk-seeking attitude whereas others have a risk-averse attitude. Environmental risk attitudes tend to correlate with they way that people view nature. Those that see nature as robust tend to be risk-seeking, those that see nature as fragile tend to be risk-averse. In between are those that have a risk-regulating attitude, corresponding to a view of nature as 'robust within limits', and those that are indifferent to risk, corresponding to a view of nature as capricious or risk as fate. (Douglas and Wildavski, 1982)

One should further be aware that being risk-averse to ecological risks is not the same as being risk-averse to economic risks. This cultural plurality in risk attitudes implies that the question of how society ought to deal with risks can only be answered in public debate - a debate in which people will necessarily discuss their perception of risks and risk management from different points of view and different conceptual and ethical frameworks (Davidson, 2002).

Third, in the case of the PP the acceptable risk approach is problematic because the uncertain nature of the risks makes it very difficult to set a safe level. Some argue that the PP reframes this choice into the question of how much harm can be avoided. Tickner (1999) for instance, illustrates that estimating a safe level of temperature increase is difficult and controversial. Reframing the question would change the focus from assessing a safe level to reducing greenhouse gas emissions as much as possible. Anyway, the international community has taken the more traditional risk approach seeking to agree on a level of protection. This is laid down in Article 2 of the UN FCCC: "The ultimate objective of this Convention (. . .) is to achieve (. . .) stabilization of greenhouse gas concentrations in the atmosphere at a level that would prevent dangerous anthropogenic interference with the climate system. Such a level should be achieved within a time frame sufficient to allow ecosystems to adapt naturally to climate change, to ensure that food production is not threatened and to enable economic development to proceed in a sustainable manner.".

The parties have not yet agreed on a quantified stabilization level for atmospheric greenhouse gas concentrations that is considered to meet this vaguely described level of protection. Because ecosystems have a maximum speed in keeping up with shifting 
climate zones, it is widely held that the rate of global warming has to be limited. Also, a maximum allowable global temperature increase has to be set. Further, in order to protect coastal ecosystems and coral reefs, limits have to be set on total sea level rise and rate of sea level rise. Finally, it is often argued that the third criterion mentioned in Art. 2, to enable economic development to proceed in a sustainable manner, can be made operational by setting a limit to the maximum rate of emission reduction per year, so protecting economies from disruption by unrealistically strict policies.

During their 1987 Villach-Bellagio workshops, the Advisory Group on Greenhouse Gasses (AGGG, the precursor of the IPCC) for the first time proposed long term climate targets for temperature change and sea level rise to protect ecosystems (Jäger, 1990). They proposed for sea level rise: a maximum rate of increase of between 2 and $5 \mathrm{~cm}$ per decade and a maximum rise of between 0.2 and $0.5 \mathrm{~m}$ above the 1990 mean global sealevel. For temperature, a maximum rate of increase of temperature of $0.1^{\circ} \mathrm{C}$ per decade was proposed, along with a maximum temperature increase of $1.0^{\circ} \mathrm{C}$ or $2.0^{\circ} \mathrm{C}$ above pre-industrial global mean temperature.

These "Villach-Bellagio targets" have played an important role in the climate policy debates since. They have inspired for instance the EU in their 6th Environment Action Programme (EC, 2001), to set a long term climate target of a maximum global temperature increase of $2^{\circ} \mathrm{C}$ over pre-industrial levels (which means $1.3^{\circ} \mathrm{C}$ above current global mean temperature) and a $\mathrm{CO}_{2}$ concentration below $550 \mathrm{ppmv}$. In December 2004 the EU revised its interpretation, stating that the $550 \mathrm{ppmv}$ target is for the $\mathrm{CO}_{2}$-equivalent concentration (all greenhouse gasses together rather than $\mathrm{CO}_{2}$ only). For $\mathrm{CO}_{2}$ this implies a stabilization level of $450 \mathrm{ppmv}$. This is likely to require a global reduction in emissions of greenhouse gases by at least $70 \%$ as compared to 1990 .

In the discourses about the quantification of such levels of protection, key arguments have been parallels with past climates and paleological insights regarding how ecosystems have responded to major natural climate changes in the past. In the following we will review the underpinnings of such quantified levels of protection for climate change.

\section{Maximum rate of warming}

Much research has been done to the climate tolerance of ecosystems and species. The speed by which ecosystems can keep up with shifting climate zones depends on many factors. A major limiting factor is the seed-cycle of trees. Analysis of pollen in sediment since the previous ice age show that maximum migration speed of trees varies between 4 and $200 \mathrm{~km}$ per century, depending on the species (Davis, 1989; Hinckley, 1997; Watson et al., 1997). For boreal forests, the speed by which climate zones shift towards the poles is critical. For Alpine ecosystems it is the speed by which climate zones shift upward. For coastal ecosystems the rate of sea level rise is critical. Roughly, a warming rate of $1{ }^{\circ} \mathrm{C}$ per century produces a rate of sea level rise of $20 \mathrm{~cm} /$ century, a poleward shift of climate zones by $100 \mathrm{~km}$ per century and a upward shift of Alpine climate zones of $150 \mathrm{~m}$. The most vulnerable ecosystems are the Alpine ecosystems. Many Alpine species are already committed to extinction for the current warming rate. Oak forests are also quite sensitive; the maximum rate of global warming with which they can keep up is estimated to be $0.12^{\circ} \mathrm{C}$ per century.

\section{Maximum allowable warming}


The fore mentioned Villach Bellagio target specified two levels for maximum temperature increase, respectively $1.0^{\circ} \mathrm{C}$ and $2.0^{\circ} \mathrm{C}$ above pre-industrial global mean tempeature. The lower temperature target was set on the basis of their understanding of the vulnerability of ecosystems to historical temperature changes. Temperature increases beyond $1^{\circ} \mathrm{C}$ could trigger rapid, unpredictable and non-linear responses that could lead to extensive ecosystem damage. The absolute temperature limit of $2^{\circ} \mathrm{C}$ was motivated as the limit beyond which the risks of grave damage to ecosystems and of non-linear responses are expected to increase rapidly.

Krause et al. (1989) have sketched a context to grasp what different levels of global warming imply, by comparing them to the climate history of the Earth:

- An increase of $1-1.5^{\circ} \mathrm{C}$ in global average surface temperature would imply a climate warmer than it ever was since 6,000 years ago in the Holocene period, which was roughly the beginning of agricultural societies.

- A $2-2.5^{\circ} \mathrm{C}$ warming would imply a climate not experienced since the so-called Eem-Sangamon interglacial period some 125,000 years ago. At that time, human society consisted of hunter gather societies and the West Antarctic ice sheet had partially disintegrated, raising sea levels by up to 5-7 meters.

- A $3-4^{\circ} \mathrm{C}$ warming would represent a climate not experienced since humans appeared on Earth (about 2 million years ago). The last time the Earth was this warm was in the Pliocene period ( 5 to 3 million years ago)

- A global average warming of $5^{\circ} \mathrm{C}$ and above corresponds to a climate not experienced for tens of millions of years. In that period there were no glaciers in the Antarctic and Greenland.

Risks for different levels of warming have been visualised qualitatively by IPCC on the basis of five risk indicators (Fig. 1). 


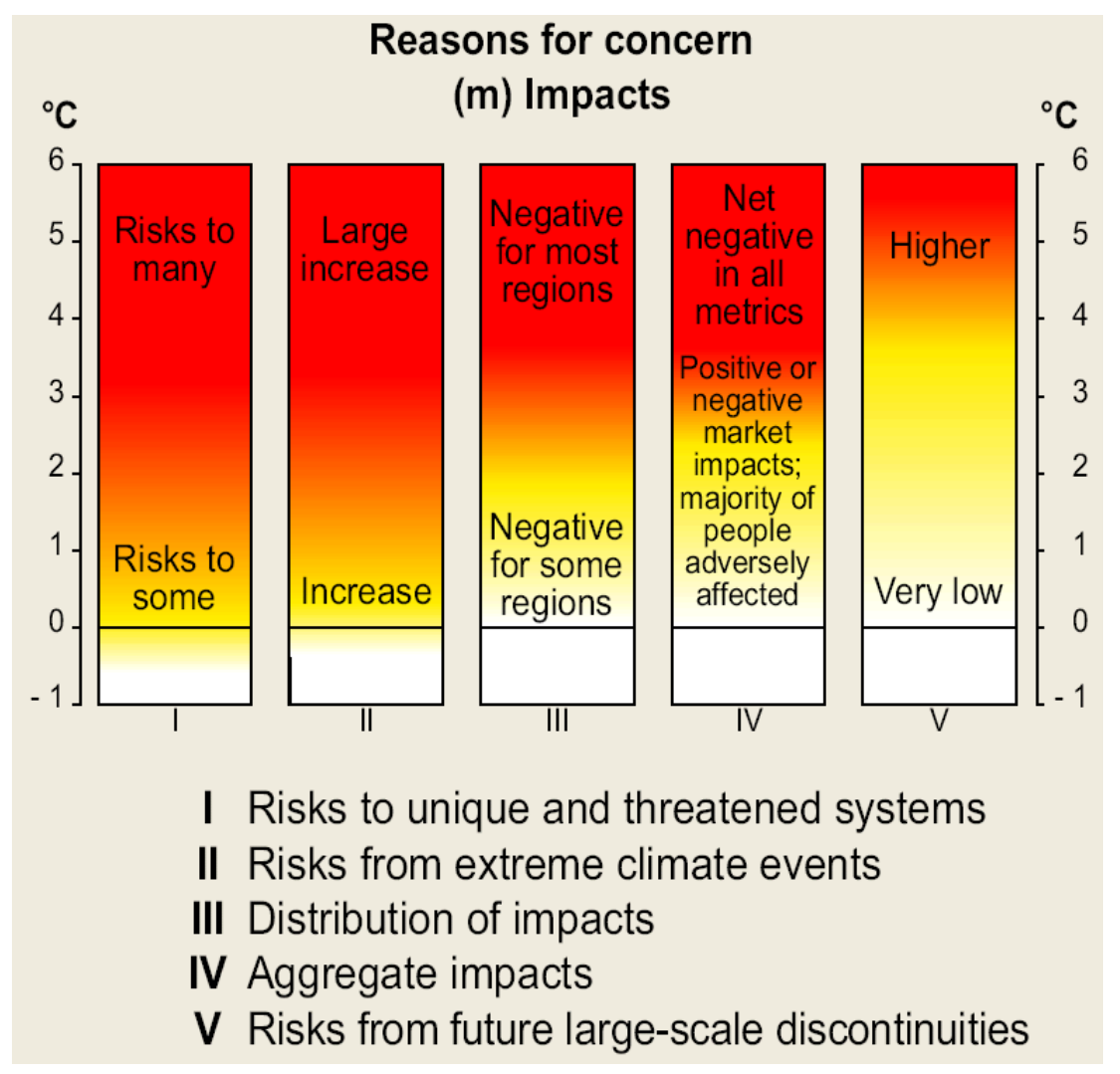

Figure 1 Risk evaluation diagram for different levels of global temperature change (IPCC, 2001)

The indicators used in this risk evaluation diagram are (IPCC, 2001):

I.Unique and threatened systems: Some changes in species and systems have already been associated with observed changes in climate, and some highly vulnerable species and systems may be at risk for very small changes in climate. Greater warming would intensify the risks to these species and systems, and place additional ones at risk.

II.Extreme climate events: Increased frequencies and intensities of some extreme events have already been observed and are likely to increase with further warming, as would the risks to human life, property, crops, livestock, and ecosystems. These risks increase where development is occurring in inherently dynamic and unstable zones (e.g., river floodplains and low-lying coastal regions).

III.Uneven distribution of impacts: In general, developing countries are at greater risk of adverse impacts from climate change than are developed countries, of which some of the latter may experience market sector benefits for warming less than a few ${ }^{\circ} \mathrm{C}$. For greater warming, most regions are at risk of predominantly negative effects from climate change. But developing countries generally would continue to be more severely impacted than developed countries. Within countries, vulnerability varies and the poorest populations often have higher exposure to impacts that threaten their lives and livelihoods.

IV.Global aggregate impacts: Globally aggregated market sector impacts may be positive or negative up to a few ${ }^{\circ} \mathrm{C}$, though the majority of people may be negatively affected. With greater warming, the risk of negative global market 
sector impacts increases, and impacts would be predominantly negative for most people.

V.Large-scale, high-impact events: The probability of large-scale, high-impact events within a 100-year time horizon such as shutdown of the THC or collapse of the West Antarctic ice sheet is very low for warming less than a few ${ }^{\circ} \mathrm{C}$. For greater warming, and over a time horizon longer than 100 years, the probabilities and the risks increase, but by an amount that cannot now be estimated.

Many ecosystems are sensitive to temperature. For instance, coral reefs around the Equator are sensitive to seawater temperature. When even during a short period the local seawater temperature exceeds $32-34^{\circ} \mathrm{C}$, coral bleaching occurs.

In a recent study, Leemans and Van Vliet (2005) found that over the last decade, many more ecological responses to climate change have been observed than expected from the average $0.7^{\circ} \mathrm{C}$ warming trend alone. Current impact assessments of climate change therefore likely underestimate ecological impacts and vulnerability. Ecosystems respond faster to changes in extreme weather than to 'normal' climate characteristics. Based on these new insights in the vulnerability of species and ecosystems, Leemans and Van Vliet suggest that the EU target is not strict enough and claim that ecosystem protection, in particular protection of coral reefs, requires to limit the increase in global mean surface temperature to $1.5^{\circ} \mathrm{C}$ above pre-industrial levels and limit the rate of change to less than $0.05^{\circ} \mathrm{C}$ per decade.

Based on the paleoclimate evidence, James Hansen, director of the NASA Goddard Space Center recently suggested that the highest prudent level of additional global warming (above the increase of $0.7^{\circ} \mathrm{C}$ already) is not more than about $1{ }^{\circ} \mathrm{C}$ if we want to avoid the risks of large scale ice sheet break up and associated extreme sea level rise. To achieve that, the atmospheric $\mathrm{CO}_{2}$ concentration should remain below 450 ppmv. (Hansen, 2004)

\section{Maximum sea level rise}

The Villach-Bellagio workshops (Jäger, 1990) proposed a maximum rate of sea level rise of between 2 and $5 \mathrm{~cm}$ per decade and a maximum rise of between 0.2 and $0.5 \mathrm{~m}$ above the 1990 mean global sea-level. Later on these targets have been criticized because they do not protect species and ecosystems that are highly sensitive to sea level rise such as coral reefs, mangrove eco systems and coastal wetlands. Mangrove ecosystems protect $25 \%$ of the tropical coastline. It is estimated that protection of Mangrove ecosystems requires that the rate of sea level rise stays below $10 \mathrm{~cm} /$ century. (Hinckley, 1997)

\section{Maximum rate of emission reduction}

The rate by which greenhouse gas emissions can be reduced without disrupting the economy is limited. This is because the existing energy infrastructure can (without capital destruction) only be changed in a time frame of several decades. Krause et al., (1990) suggest a maximum rate of emission reduction of 2-3\% per year. Other studies that focus on energy efficiency improvement, renewables, technology development and structural changes of economies are more optimistic and suggest percentages up to $4 \%$ per year (see for an overview, Van der Sluijs and Turkenburg, 1998). 
Overall, the original Villach-Bellagio targets that were the basis for the EU target of $2{ }^{\circ} \mathrm{C}$ over pre-industrial levels which translates into 550 ppmv $\mathrm{CO}_{2}$ equivalents, is increasingly challenged as being insufficient to protect ecosystems and prevent non linear climate change. As we saw, Leemans and Van Vliet (2005) make a case for a limit of $1.5^{\circ} \mathrm{C}$ to protect eco systems, whereas Hansen (2004) argues that a $1.7^{\circ} \mathrm{C}$ limit is required to avoid the risk of large-scale ice sheet break down.

In any case, even for the presently agreed levels of protection, prevention of dangerous anthropogenic interference with the climate will require drastic greenhouse gas emission reductions, particularly of $\mathrm{CO}_{2}$. Options with major potentials to achieve this are energy efficiency improvement, renewable energy sources, $\mathrm{CO}_{2}$ capture and storage and nuclear energy. The latter two options can also involve major uncertain risks that may require a precautionary approach as well. It is however beyond the scope of this chapter to discuss these issues in detail.

\section{Implications of the Precautionary Principle for Risk Management}

In risk management based on the prevention principle, risks can be managed by agreeing on an acceptable risk level for the activity and putting enough measures in place to keep the risk below that level. This approach is workable if the risks are well known and quantifiable in a credible way. The PP however deals with risks with poorly known outcomes and poorly known probability, making this traditional approach problematic. The PP asks for a number of changes in scientific culture and in the way in which risk assessment and risk management are performed (Harremoes et al., 2001; Grandjean et al, 2003; UNESCO COMEST, 2005). In the following we will discuss these with a focus on the climate change case.

\section{Coping with uncertainty}

The PP requires a science that better reflects uncertainty and complexity in the assessment of risks. Both qualitative and quantitative dimensions of uncertainty need explicit treatment. Uncertainties along with the key assumptions on which knowledge claims on risks are conditioned need to be made explicit and communicated clearly to the various actors involved in the discourse on these risks. This requires the further development and dissemination of multidisciplinary and multidimensional uncertainty analysis, which enables the delivery of policy-relevant quantitative information on risks together with the essential warnings about its uncertainties, limitations and pitfalls (Van der Sluijs et al., 2005). The PP imposes a clear need to improve communication and reflection on various levels and types of uncertainty in scientific assessment. There is a pitfall to present high impact events of which the knowledge is so uncertain that there is no ground to estimate the probability as "low probability high impact events". We argue that it is better in such cases to talk about "poorly-known-probability, high impact events". Patt (1999) has shown that the consensus building process in climate risk assessment tends to lead to strategic treatment of poorly-known probability high-impact events: those issues on which no consensus can be achieved are underaddressed or ignored (e.g. by qualifying them as "low probability") whereas such issues may well be policy relevant. As a consequence, in the development of many climate policy plans, non-linearity and surprise have been under-addressed and worst-case scenarios have not been included. Possible impacts in the case of warming with more 
than $4^{\circ} \mathrm{C}$ or impacts for the case that (regionally) climate would cool rather than warm have not been considered. Assessments have hardly looked beyond the year 2100. The focus has been on the state of the climate, while the trajectory of accelerated climate change and the committed climate change might be more important. All these omissions make society less prepared to possible surprises and potential disasters. (Van der Sluijs et al., 2002)

At present, poorly known probability high impact events are getting little attention in climate risk management, when objectively speaking, they may present a similar level of risk as say, high probability-low impact events. In a precautionary approach, extreme events, surprises and worst-case scenarios should get a more prominent role in risk assessment and in the development of mitigation, adaptation and back stop options such as $\mathrm{CO}_{2}$ capture and storage capacity. Decision making under uncertainty further requires flexibility which can be related to timing of investments in e.g. energy infrastructure, timing with regard to tree-cycles in forestry etc. It also requires reversibility of policies and adequate monitoring of compliance and effectiveness of policies. Finally, more focus will need to be put on the consequences of a possible failure of the international community to timely stabilize atmospheric greenhouse gas concentrations at a safe level.

Enhance the role of vulnerability science: systematic search for surprises and ways to constrain them

To reiterate, models anticipate climate change well beyond the natural variability of the climate in the past millennia. The past is thus no longer a reliable key to the future and we can expect to meet surprises in our collective journey into Terra Incognita. Given the absence of adequate methodology to assess surprise, a systematic search for examples of surprises and non-linear system behaviour from the past might be the prelude to a search for possible surprises in the future (Brooks, 1986). Other strategies that can help us to anticipate surprise include focusing on the underlying principles of surprise, which is what happens in surprise theory (Holling, 1986) and systematic 'thinking the unthinkable' by imagining unlikely (undesirable) future events or future states of the environment, followed by the construction of plausible scenarios by which they might be realized. From such an analysis we then hope to be able to identify precautionary intervention strategies that constrain the possibilities of the system at hand to develop towards such undesired states (Kates and Clark, 1996).

A growing body of evidence as produced by paleoscientific studies reveals that major dynamic patterns, teleconnections and feedback loops in the total Earth System can be flipped to different modes of operation by internal and external perturbations of which the thermohaline circulation regime is only one example. Revealing the mechanisms that bring about such "extreme events" in the coupled nature-society system is a major scientific challenge. Novel approaches are needed that take full advantage of state of the art nonlinear dynamics and complexity theory (e.g. Bunde et al., 2002; Petschel-Held, 1999). A key challenge here is the advancement of vulnerability science, which is able to identify in modelled responses of systems to multiple perturbations and stresses, those directions that represent a catastrophic risk to the system at stake. (Schellnhuber, 2004)

\section{Enhance the role of monitoring and empirical research}


One of the difficulties in understanding complex environmental systems is that shortterm observations (even of decades or a century) may be too short to reveal the full range of possible behaviors of the system. Scientists cannot use observations to demonstrate the existence of an alternative state that has not, for instance, appeared in the observational record. Therefore, the PP requires further development of models of integrated social-ecological systems that exhibit complex behaviors on a variety of spatial and temporal scales. These models, which may reveal the existence of undesirable states and give some indication of the warning signals of change from one state to another must be accompanied by a more intensive effort in monitoring. By placing a greater emphasis on direct measures to systematically monitor observable effects, a precautionary approach offers a way to be more responsive to harm when the first signals of it manifest themselves in the real world, however ambiguous these first signals may be. By an active search for early warnings, one can hope to significantly reduce society's exposure to uncertainty and ignorance. For the case of the thermohaline circulation, Deutsch et al. (2002) have shown that a monitoring system to detect changes in THC in time to be useful for climate policy is possible by more and more frequent observations. They argue that the benefits of such an improved ocean observation system would considerably exceed the costs.

\section{Search for robust solutions that increase resilience}

Climate policy planning studies often take an average scenario for climate change as a starting point for the risk management strategy. By doing so, the strategy is not adequate in the case that a THC shutdown would cause a regional cooling in Western Europe. In searching adaptation options one should strive for measures that are robust against such uncertainties. Such measures reduce the damage for both possible outcomes - warming and cooling. A key concept here is resilience. Resilience is the capacity of a system to tolerate disturbance without collapsing into a qualitatively different - usually undesired - state. For instance, a resilient ecosystem can withstand shocks and rebuild itself when necessary. Resilience in social systems includes the capacity of humans to anticipate and plan for the future, and to adapt to inevitable unanticipated conditions. Humans depend on ecological systems for survival and their actions are continuously impacting ecosystems from the local to the global scale. Resilience is a property of these linked social-ecological systems. Resilience has three characteristics: (1) the amount of change the system can undergo and still retain the same controls on function and structure, (2) the degree to which the system is capable of self-organization, (3) the ability to build and increase the capacity for learning and adaptation. The first two are also the focus of vulnerability science and fostering of the third should be a central element of any precautionary governance.

In the case of forest-management, robust measures include increasing the biodiversity and improving the water-balance of the forest. In the case of food production robust adaptation measures can be increasing the diversity of crops, developing crops with a broad climate and water tolerance, improve the management system for the water balance (irrigation and drainage), implementing food storage and distribution programs to cope with crop failures, increasing trade in food products and providing insurance to enable farmers to cope with crop failures. For extreme weather events (storms, floods, droughts etc.) robust adaptation options could include the development of early warning systems, land use controls in vulnerable area's, developing insurance and compensation 
arrangements, modifying building codes and setting up international cost sharing mechanisms.

Be more realistic about the role and potential of science in assessment of complex risks Precaution entails a greater degree of humility or realism over the role and potential of science in assessment of risks. Scientific and technical evidence and analysis remain essential. However - under a precautionary approach - scientific analysis is seen as a necessary, rather than a sufficient, basis for effective policy choices.

More realism is also needed in the level of precision and confidence with which findings of risk assessment are expressed. The present focus on the quest for hard evidence rather than on the relative likelihood and plausibility of risks needs revision. Scientists are not bound to remove uncertainty - at least this may not be their primary task - but they can inform society about possible risks, on the background of what may be relevant for their audiences. Instead of a one sided focus on 'hard evidence', plausibility requires scientific reasoning in order to explain certain observations or hypotheses so they make sense to both expert and non-expert audiences and appeals to their understanding of the problem.

Increase societies capacity to act upon uncertain early warnings

As a reviewer of this chapter pointed out, one could argue that scientists have been providing us with early warnings of climate change for at least two decades now. Although scientists could do so in a better and more sophisticated way, there also is an urgent need of the greater societal risk management process to cope with and act upon such uncertain warnings. The "Late lessons from early warnings" report (Harremoës et al., 2001) provides a number of recommendations in this regard, such as maintaining regulatory independence, identification and reduction of institutional obstacles to learning and action and avoidance of paralysis by analysis.

\section{Knowledge partnerships for precaution and sustainable development}

The PP implies a need for trans-disciplinary approaches to science and policy. Science for policy in the face of uncertainty requires new trans-disciplinary contacts and integration (internal extension of the peer community) on the one hand, and new contacts with policy makers, non governmental organizations (NGOs), industry, media and the public (external extension of the peer community) on the other hand to meet the challenges of quality control in the assessment of complex risks.

Because of the many uncertainties, traditional science is not able to sufficiently support drastic steps that may sometimes be needed to deal with complex risks. The traditional dominance of 'hard facts' over 'soft values' has been inverted: hard value commitments may have to be made - even in the course of research design - based on soft facts. The assessment of risks and the setting of policy should therefore encompass public agreement and participation.

The knowledge and perspectives of stakeholders can bring in valuable new views and relevant information on that problem. Stakeholders can contribute to knowledge on local conditions which may help determine which data are strong and relevant or which response options are feasible: They may provide personal observations on the risk and its effects, which may lead both to new foci for empirical research, addressing 
dimensions of the problem which were previously overlooked and to creative thinking about mechanisms and scenarios through which different sectors of society may be affected. Making full use of this reservoir of extra knowledge requires the establishment of an extended peer community not only in the phase where response options are debated, but also in the problem-framing and risk assessment processes that precede it.

Further materialization of the PP requires not only a change towards a deliberative societal process of climate risk management but also a change in climate risk assessment towards fully-fledged management of uncertainty, inclusion of minority views and extended peer review of underlying assumptions.

New platforms need to be established that bring together stakeholders, scientists working on evaluating risks and scientists working on options for risk reduction and more sustainable energy technologies and systems.

\section{Conclusion}

Managing the risks of anthropogenic climate change imposes a major challenge to society. A number of possible irreversible large-scale non-linear impacts of climate change has been identified, including a regime shift in the large scale ocean circulation, extreme sea level rise if ice sheets disintegrate and extinction of large numbers of species. Although our state of knowledge suggests that on the long term such impacts are plausible, it is not yet possible to quantify the magnitude and probability of each of these potential effects. To protect human societies and ecosystems to these risks, climate change should be kept within limits. A widely agreed limit for maximum acceptable warming is at present $2^{\circ} \mathrm{C}$. Current projections of climate change for the coming century exceed this limit, showing the necessity of drastic emission reductions.

Present day atmospheric greenhouse gas concentrations are outside the range of natural variability of the past half million year. Model studies anticipate climate change in the coming century well beyond the natural variability of the climate in the past millennia and a possibility of a climate not experienced for tens of millions of years (more than $5^{\circ} \mathrm{C}$ warming). The past is thus no longer a reliable key to the future and we can expect to meet surprises in our collective journey into Terra Incognita.

A precautionary approach is needed and this requires a number of changes in scientific culture and in the way risk assessment is performed. Uncertainty management has to be further improved, vulnerability science should be promoted and a more systematic search for possible surprises and ways to avoid undesired states of the Earth system is needed. Monitoring and empirical research need be enhanced with a special focus on detection and early warning systems, to timely detect occurrence of possible large-scale instabilities in the climate system. Risk management strategies need to focus on robustness, resilience and disaster preparedness. More realism is needed regarding the role and potential of science in assessing complex risks. There is a need of the greater societal risk management process to cope with and act upon uncertain early warnings. Finally, further development of knowledge partnerships for sustainable development, involving scientists, stakeholders and the public, are crucial in achieving effective climate risk management. 


\section{References}

Alley, R. B. (2003) 'Palaeoclimatic insights into future climate challenges', Phil. Trans. R. Soc. Lond., A361, 1831-1849.

Brooks, H. (1986) 'The Typology of Surprises in Technology, Institutions and Development', in Clark W.C. (ed.), Sustainable Development of the Biosphere, New York: Cambridge University Press, pp. 325-348.

Bunde, A, Kropp, J., and Schellnhuber, H. J., (eds.) (2002) Science of Disasters, Springer, Heidelberg.

Davidson, M.D. (2002) 'Treating future generations as equals with respect to risk and uncertainty', paper presented at Risk and Uncertainty in Environmental and Resource Economics, Wageningen, June 5-7, 2002, http://www.sls.wau.nl/enr/conference/papers/long/Davidson_long.doc, 23 November 2004.

Davis, M.B. (1989) 'Lags in Vegetation Response to Greenhouse Warming', Climatic Change, 15, 75-82.

Dessai, S., and M. Hulme (2004), 'Does climate adaptation policy need probabilities', Climate Policy, 4 (2), 107-128.

Deutsch, C., M.G. Hall, D.F. Bradford, and K. Keller (2002), 'Detecting a potential collapse of the North Atlantic thermohaline circulation: Implications for the design of an ocean observation system', Paper presented at the Energy Modelling Forum Summer Workshop Climate Change Impacts and Integrated Assessment VIII, Snowmass, Colorado, July 27 - August 7, 2002.

Douglas, M. and A. Wildavsky (1982), Risk and Culture: An Essay on the Selection of Technological and Environmental Dangers, Los Angeles: University of California Press.

European Commission (2001) 6th Environmental Action Plan, Brussels: European Commission.

European Environment Agency (2004), Impacts of Europe's Changing Climate, Copenhagen: European Environment Agency.

Grandjean P, Sofritti M, Minardi F, Brazier J, (eds.) (2003), The Precautionary Principle. Implications for research and prevention in environmental and occupational health. Eur J Oncol Library 2:1-245, www.collegiumramazzini.org/links/PPcontentspage.htm, 17 May 2005.

Hansen, J. (2004), 'Defusing the Global Warming Time Bomb', Scientific American, March 2004. 
Harremoës, P., Gee, D., MacGarvin, M., Stirling, A., Keys, J., Wynne, B., and Guedes Vaz, S. (eds.) (2001), Late lessons from early warnings: the precautionary principle 1896-2000, Environmental issue report no. 22. Copenhagen: European Environment Agency.

Hinckley, D. (1987), 'Setting Ecological Goals under the Climate Change Convention', paper presented at the 8th Global Warming Conference and Exposition, Columbia University, New York, May 28, 1997.

Holling, C.S. (1986) 'The Resilience of Terrestrial Ecosystems: Local Surprise and Global Change', in: Clark W.C. and R.E. Munn (eds.) Sustainable Development of the Biosphere, Cambridge: Cambridge University Press, pp. 292-317.

Houghton, J.T., G.J. Jenkins, and J.J. Ephraums (eds.) (1990), Climate Change, The IPCC Scientific Assessment, Cambridge: Cambridge University Press.

Houghton, J.T.. L.G. Meira Filho, B.A. Callander, N. Harris, A. Kattenberg, and K. Maskell (eds.) (1996), Climate Change 1995, The Science of Climate Change, Contribution of Working Group I to the Second Assessment Report of the Intergovernmental Panel on Climate Change (IPCC), Cambridge: Cambridge University Press.

Houghton, J. T., Y. Ding, D.J. Griggs, M. Noguer, P. J. van der Linden and D. Xiaosu (Eds.) (2001), Climate Change 2001: The Scientific Basis, Contribution of Working Group I to the Third Assessment Report of the Intergovernmental Panel on Climate Change (IPCC), Cambridge: Cambridge University Press, 2001.

IPCC (2001), Climate Change 2001: Synthesis Report, Geneva: IPCC.

Jäger, J. (1990), Responding to Climate Change: Tools for Policy Development, Stockholm: The Stockholm Environment Institute.

Kates R.W. and W.C. Clark (1996), 'Expecting the unexpected', Environment, 38 (2), 611 and 28-34.

Krause, F., W. Bach, J. Koomey, (1989), Energy Policy in the Greenhouse, International Project for Sustainable Energy Paths, Cerrito, California: International Project for Sustainable Energy Paths (IPSEP).

Leemans, R. and A. van Vliet (2005) Extreme weather: does nature keep up? Wageningen University, Environmental Systems Analysis Group, Wageningen.

Mercer, J.H. (1970) 'Antarctic Ice and Interglacial High Sea Levels', Science, 168, 1605-1606.

Mercer, J.H. (1978) 'West Antarctic ice sheet and $\mathrm{CO}_{2}$ greenhouse effect: a threat of disaster', Nature, 271, 321-325. 
Millennium Ecosystem Assessment (2005) Millennium Ecosystem Assessment Synthesis Report, Washington, DC: Island press.

Murphy, J.M., D.M.H. Sexton, D.N. Barnett, G.S. Jones, M.J. Webb, M. Collins, and D.A. Stainforth, (2004), 'Quantification of modelling uncertainties in a large ensemble of climate change simulations', Nature, 430, 768-772.

Nakicenovic, N. and R. Swart (Eds.) (2000), Emissions Scenarios. 2000, Special Report of the Intergovernmental Panel on Climate Change, Cambridge: Cambridge University Press.

Patt, A. (1999), 'Extreme Outcomes: The Strategic Treatment of Low Probability Events in Scientific Assessments', Risk, Decision and Policy, 4 (1), 1-15.

Petschel-Held, G., A. Block, M. Cassel-Gintz, J. Kropp, M. K. B. Lüdeke, O. Moldenhauer, F. Reusswig, and H. J. Schellnhuber (1999), 'Syndromes of Global Change: A Quantitative Modelling Approach to Assist Global Environmental Management', Environmental Modeling and Assessment 4, 295-314.

Petit, J. R., J. Jouzel, D. Raynaud, N.I. Barkov, J.-M. Barnola, I. Basile, M. Bender, J. Chappellaz, M. Davis, G. Delaygue, M. Delmotte, V.M. Kotlyakov, M. Legrand, V.Y. Lipenkov, C. Lorius, L. Pépin, C. Ritz, E. Saltzman, M. Stievenard (1999), 'Climate and atmospheric history of the past 420,000 years from the Vostok ice core, Antarctica', Nature, 399, 429-436.

Rahmstorf, S. (1995), 'Bifurcations of the Atlantic Thermohaline Circulation in Response to Changes in the Hydrological Cycle', Nature, 378, 145-149.

Schellnhuber, H. J. (2004) 'The Scientific Search for the Limits of sustainability', sustsci.harvard.edu/questions/limits.htm, 21 November 2004

Stainforth D.A., T. Aina, C. Christensen, M. Collins, N. Faull, D. J. Frame, J. A. Kettleborough, S. Knight, A. Martin, J. M. Murphy, C. Piani, D. Sexton, L. A. Smith, R. A. Spicer, A. J. Thorpe and M. R. Allen (2005), 'Uncertainty in predictions of the climate response to rising levels of greenhouse gases', Nature, 433, 403-406.

Steffen, W. and P. Tyson (eds) (2001), Global Change and the Earth System, A planet under pressure, IGBP Science Series 4, Stockholm: International Geosphere Biosphere Programme.

Stocker, T.F. R. Knutti, and G. Plattner (2001), The Future of the Thermohaline Circulation A Perspective, in Seidov, D., M. Maslin, and B. J. Haupt (eds) The Oceans and Rapid Climate Change: Past, Present, and Future, Volume 126 of Geophysical Monograph, Washington, D. C., Am. Geophys. Union, pp. 277-293.

Thomas C.D., A. Cameron, R.E. Green, M. Bakkenes, L.J. Beaumont, Y.C. Collingham, B.F.N. Erasmus, M. Ferreira de Siqueira, A. Grainger, L. Hannah, L. Hughes, B. Huntley, A.S. van Jaarsveld, G.F. Midgley, L.Miles, M.A. Ortega-Huerta, 
A. Townsend Peterson, O.L. Phillips and S.E. Williams (2004) 'Extinction risk from climate change', Nature, 427, 145-148.

Tickner, J. (1999). 'A map toward precautionary decision making'. In: Tickner, J. \& Raffensperger, C. (eds.) Protecting Public Health and the Environment Implementing the Precautionary principle, 162-186. Island Press, Washington, D.C/Covelo, Californina.

Titus, J.G. (1986) 'The causes and effects of sea level rise', in Wind, H.G. (ed.) Impact of Sea Level Rise on Society, Rotterdam: A.A.Balkema.

UN-FCCC (1992) United Nations Framework Convention on Climate Change, United Nations.

UNESCO COMEST (2005) Report of the Expert Group on the Precautionary Principle of the World Commission on the Ethics of Scientific Knowledge And Technology (COMEST), Paris: UNESCO COMEST.

Van der Veen C.J. and J. Oerlemans (1987) Dynamics of the West Antarctic Ice Sheet, proceedings of a workshop held in Utrecht, May 6-8, 1985, Dordrecht: D. Reidel Publishing Company.

Van der Sluijs, J.P., M. Craye, S. Funtowicz, P. Kloprogge, J. Ravetz, and J. Risbey (2005), 'Combining Quantitative and Qualitative Measures of Uncertainty in Model based Environmental Assessment: the NUSAP System', Risk Analysis, 25 (2) 481-492.

Van der Sluijs, J.P., M. Hisschemoller, J. de Boer, P. Kloprogge (2002), Climate Risk Assessment Evaluation of Approaches, Summary and synthesis report. Utrecht: Utrecht University, Department of Science Technology and Society.

Van der Sluijs, J.P. and W.C. Turkenburg (1998), NMP 3 thema klimaat: een kritische analyse van het probleemveld, de beleidsdoelstellingen en de maatregelen, The Hague, VROM-Raad.

Vlek, C. (2004), 'Environmental versus individual risk taking: perception, decision, behaviour'. In: Spielberger, C. (ed.), Encyclopedia of Applied Psychology, San Diego (Cal) Academic Press.

Von Schomberg, R. (2004), 'The Normative Dimensions of the Precautionary Principle and its Relation to Science and Risk Management Decisions' in: Achen, T. (ed.)

Microscopic Modification and Big Politics, Linkoeping Studies in Arts and Science, Vadstena, Sweden.

Watson, R., M.C. Zinyowera, R. H. Moss and D.J. Dokken (1997) The Regional Impacts of Climate Change: An Assessment of Vulnarability, IPCC Special Report, Geneva: IPCC.

Wigley T.M.L. (2005), The Climate Change Commitment, Science, 307, 1766-1769. 
Wood, R.A., M. Vellinga and R. Thorpe (2003), 'Global warming and thermohaline circulation stability', Philosophical Transactions of the Royal Society of London, $\mathbf{3 6 1}$ (1810): 1961-1974. 